\title{
Contingencias de las Estructuras Familiares del Milenio
}

Contingencies of the Family Structure of the Millennium.
Recibido: Enero 2008 revisado: Junio 2008 aceptado: Enero 2009
Por: Ángela María Quintero Velásquez*

\section{Resumen:}

La Familia como la máxima institución social, ha cambiado en su estructura, funcionamiento y ciclo vital. Es considerada como un sujeto prevalente de derechos y un nuevo actor social, a nivel nacional e internacional. En sus relaciones ecosistémicas, dinámicas, flexibles y adaptativas, es influenciada por los fenómenos socio-económicos, culturales y políticos del tercer milenio, que afectan todas la estructuras familiares, según su estrato socio-económico y condiciones. El artículo referencia algunos de los eventos, que deben ser considerados en la formación profesional universitaria, en la formulación de política pública y en la modernización de las legislaciones que amparan a la familia o a sus miembros. Tales son: Modernización del Estado y reformas legislativas, Movilidad social. Remesas Familiares. Desplazamiento forzado. Desigualdad en el capital humano. Empresas familiarmente responsables. Desarrollo sustentable. Relación familia escuela. Homoparentalidad. TICS. Tecnologías de la información.

Palabras claves: familia, estructura, desarrollo humano, políticas públicas, derechos humanos, legislación.

\section{Abstract:}

The family, as the maximum social institution, has changed in its structure, functioning and vital cycle. It is considered as a prevalent subject of rights and a new social actor, nationally and internationally. In its ecosystemic, dynamic, flexible and adaptive relationships, it is influenced by the socioeconomic, cultural and political phenomena of the third millennium, which affect all the family structures; according to its socio-economic status and conditions. This article makes reference to some of the events, which must be taken into account in the college professional training, in the formulation of a public policy and in the modernization of the legislations which protect the family or its members. Such legislations include: the Modernization of the State and legislative reforms, Social Mobility, Family Remittance, Forced Migration, Economic Inequality in the human capital, Responsible Family Enterprises, Sustainable Development, Family-School Relationship, Homoparentality, Information and Communication Technology.

Keywords: Family; Structure; Human Development; Public Policies; Human Rights and Legislation.

\footnotetext{
* Docente Investigadora Universidad de Antioquia
} 


\section{Introducción}

Finalizando la primera década del milenio, es evidente que la Familia como la máxima institución social, es permeada por factores de diversa índole que establecen resonancias significativas en toda su organización y en sus interacciones ecosistémicas. Asumiendo novedosas tipologías y categorías de funcionamiento, permeables y adaptadas al Cambio de Época.

No sólo emergen nuevas estructuras familiares, que desde el orden cultural, impactan a la sociedad, sino que todas las transformaciones planetarias, necesariamente afectan e influyen a los grupos humanos. Es impensable en pleno siglo XXl, plantear que se está exento de las vicisitudes contemporáneas y que éstas pueden ser controladas, evitadas o neutralizadas, o en el mejor de los casos, que el quehacer humano puede sucederse ignorando el contexto.

Las eventualidades de la centuria, convocan a asumir cosmovisiones personales, ciudadanas y profesionales, acordes con el enfoque sistémico, el pensamiento complejo, la teoría del caos y los desarrollos alternativos (escala humana y sostenible), que favorecen una explicación mas plausible del acontecer y proposiciones innovadoras para comprender y asumir los dilemas humanos.

Ante contextos globales, mundiales, inciertos y ambiguos se requieren respuestas locales y nacionales a problemas supranacionales. La realidad es multipolar, no existe un sólo universo sino la multidiversidad (la unidad en la diversidad), diferentes percepciones o mundos multisituados. El giro de paradigma, se corresponde con las hendiduras en los modelos religiosos, políiticos, económicos y culturales, la caída del Muro de Berlín, el reordenamiento capitalista del sistema económico chino, la emergencia de variados cultos y el fundamentalismo religioso, transforman la geopolítica mundial.

En relación con las dimensiones sociales de la globalización, han surgido nuevos actores que juegan en el concierto mundial: los actores no estatales y los movimientos por la ampliación de la ciudadanía de diversos tipos. Desde esa perspectiva, cabe destacar la extensión gradual de ideas y valores globales, como los Derechos Humanos, el desarrollo social, la equidad de género, el respeto a la diversidad étnica y cultural, la protección del medio ambiente y otros consagrados en las Cumbres Mundiales de las Naciones Unidas. Los valores asociados a la igualdad de Derechos -especialmente para las mujeres y los niños, entran en contradicción con los valores tradicionales sociales y, en especial, con los familiares. (Arriagada; 2009: 116)

El orbe contemporáneo evidencia choque de civilizaciones, diálogo intercultural, trascendencia de lo global, exacerbación de nacionalismos, de migraciones, exilios y desplazamiento forzado. En un contexto creciente de urgencias prácticas, de conflictos sociales y catástrofes ecológicas, económicas y políticas, los diferentes actores sociales adquieren posiciones que 
remozan las tensiones clásicas, a la vez que plantean problemas inéditos, frente a los cuales el despliegue de la lógica cartesiana, simbolizada en el desarrollo acelerado, desigual e inequitativo de la ciencia y la tecnología, requiere otros dispositivos de comprensión y abordaje.

La noción moderna de la filosofía política, enmarca el precepto de que es en la dimensión cultural del desarrollo desde donde es viable construir un proyecto de país, de región, de ciudad. Entendiendo por cultura además de las bellas artes, las concepciones del mundo, las formas de comunicación entre los seres humanos y de relación con su entorno natural, para trasformarlo, re-crearlo y enriquecerlo. La modernidad política, acoge las nociones de Cultura ciudadana y ética civil, que facilitan la inclusión de nuevos actores sociales y políticos, como lo es la Familia, en el cumplimiento de sus funciones históricas (proceso de socialización y protección psico-afectiva).

En el imperativo de la causalidad circular, del pensamiento holístico, los sistemas humanos corresponden con este contexto, derivando a los principios rectores la familia, concebida como la única institución perenne en las organizaciones humanas, transmutable a la par de la sociedad y viceversa. Su función innata de la adaptabilidad ha permitido que asimile los cambios de contexto y a su vez influya en las transformaciones globales.

Por ello, la estructura, el funcionamiento y la evolución de la familia, ha transmutado según las exigencias del entorno, para adquirir nuevas denominaciones y características que la diferencian sustancialmente de la Familia de otras épocas. Este es el principio conceptual que afirma que el estudio, el análisis y la intervención holística de la Familia, requiere comprender sus perspectivas básicas de estudio en interacción permanente: estructural, funcional, evolutiva y sistema de creencias.

Uno de los objetivos de este documento, mas que recapitular sobre las tipologías o estructuras familiares, es esbozar elementos del entorno y de la complejidad de los tiempos, que impactan, modifican a la familia como una totalidad, como un sistema relacional, permeable, en permanente proceso de adaptabilidad y reajuste interno, por su condición progresiva. "Una definición completa de familia incluye por lo tanto tres perspectivas: una estructural, relativa a los aspectos de composición, jerarquía, límites, roles, subsistemas, etc.; otra funcional, relacionada con los patrones y fenómenos de la interacción, y otra evolutiva como un sistema morfogenético en creciente complejidad. (Hernández; 1997: 29).

En esta propuesta científica, la provocación inherente es asumir el Lenguaje Especializado, la cosmovisión holística, el Cambio de Época, la ética civil y ciudadana, a abandonar los discursos ideológicos, vacíos de significado y excluyentes, para aportar en el proceso de construcción social de la Familia y el Género en su relación dialéctica. Es necesario abandonar la visión unidimensional porque hay una pluralidad de caminos hacia la modernidad.

La Familia es el máximo sistema social por excelencia, dinámico, evolutivo, flexible, permeable, 
todo ello para resaltar su función básica, la Adaptabilidad, que le permite contener y manejar las situaciones de cambio tanto internas como externas, previstas o imprevistas, en el conjunto de las relaciones ecosistémicas y de la interacción entre los procesos individuales, familiares, institucionales y sociales. La noción fundamental de familia, está también mediada, por el parentesco consanguíneo, la convivencia y la red relacional, para abarcar la estructura, la función y el ciclo vital contemporáneos.

Las transformaciones de la familia, tienen que ver con modificaciones en su estructura, en su funcionamiento y en su evolución, cada cual es de una índole particular y merece ser analizada en su contexto, mediante la intersección entre las dinámicas internas y las externas, que finalmente obedece a las relaciones ecosistémicas, que sitúa la reflexión en la recursividad y circularidad de los procesos humanos y el imperativo de abordarlos en la complejidad y la colaboración de las áreas del conocimiento. Las innovaciones no son sólo en estructuras, sino en modelos y enfoques de intervención y de acción social

La naturaleza multidisciplinaria del análisis, comprensión e intervención de la familia, está sustentada por diversos autores, investigadores, docentes que la incluyen ya en al agenda universitaria, científica y en las escuelas de pensamiento. Ante la coexistencia de dispositivos y repertorios profesionales clásicos, con estrategias de vanguardia, que atiendan la complejidad de los tiempos y las contingencias de la época, se requieren competencias técnicoinstrumentales y científicas que integren los procedimientos clásicos, con los nuevos desafíos y el Cambio de Época. Esto es reconocer que coexisten los conocimientos y las metodologías tradicionales, con las contemporáneas.

La familia ha sido, sin duda, uno de los actores sociales que ha vivido transformaciones más profundas. En efecto, sobresale la coexistencia de distintas dinámicas económicas y culturales que operan en la composición descomposición-recomposición de formas familiares, parcialmente como expresión de la fragmentación de la sociedad colombiana y también de sus procesos diferenciales de inclusión - exclusión... los cambios paulatinos pero progresivos de las relaciones de género y en particular el papel de la mujer, han incidido también en la evolución de la familia colombiana...Como uno de los lugares centrales de la expresión de la vida privada, la familia también es una de las instituciones importantes en los procesos de consolidación de lo público. En primer lugar, porque resulta decisiva como soporte económico, social, cultural y afectivo para los miembros de la sociedad... Es un centro muy importante de los procesos de identidad social e individual y uno de los referentes que las personas suelen mantener durante toda su vida. Así se constituye en uno de los eslabones claves del tejido, más denso y amplio, de la sociedad. (Garay, 2002: 1 19-121)

Es un deber académico, profesional y ético, invocar siempre en estos temas a la Maestra Virginia Gutiérrez de Pineda (1923 Socorro-1999 Bogotá), por ser la primera mujer, investigadora, antropóloga, docente y científica social de la Universidad Nacional de Colombia, que estudió el tema de la Familia como unidad de análisis metodológico. Sustenta el concepto del poliformiso familiar, para comprender que existen variedad de organizaciones familiares, según 
el contexto socio-económico, la cultura y la identidad regional. Con el cambio de milenio, el término deriva a Diversidad Familiar, que permite asumir la coexistencia de las familias tradicionales, las nuevas organizaciones y los hogares no familiares, en razón de su Estructura, pero atendiendo el funcionamiento y evolución propia de cada una, comporta propiedades exclusivas.

En la línea del lenguaje especializado, la comunidad científica acoge la definición, resultado de una investigación terminológica-documental, de tipo interinstitucional, interdisciplinaria e intersectorial, del tema central:

\subsection{Estructura Familiar, (Family Structure)}

Organización interna de las relaciones, los patrones y las reglas del grupo familiar, se evidencia en los diversos subsistemas que la componen, posibilitando así las interacciones permanentes entre los diferentes miembros, a partir de las pautas, reglas, costumbres, límites, entre otros. Rige el funcionamiento individual y familiar, define su conducta, facilita su interacción recíproca, permite realizar sus tareas esenciales, apoya el desarrollo afectivo y evolutivo de sus miembros y les proporciona un sentimiento de pertenencia. Está configurada alrededor de los cambios sociales, en la renovación y contextualización permanentes de las pautas transaccionales que han operado a lo largo de la historia de la sociedad y por ende de la familia. Es dinámica y está determinada por un tiempo y espacio específico. Sus elementos constitutivos son, el parentesco, la edad, el sexo de los integrantes y el vínculo de la pareja, esto imprime una identidad propia a cada familia y establece la identidad de género y los subsistemas con sus respectivas fronteras, jerarquías e interdependencias facilitando así las relaciones interpersonales y con los contextos significativos. (Quintero, 2007: 57)

\subsection{Eventos Influyentes en las Estructura Familiares.}

Lo anteriormente planteado como propósito de este documento, de omitir explícitamente la apología o caracterización de las estructuras o tipologías familiares - lo suficientemente ilustradas-, da lugar a la enunciación de fenómenos sociales que inciden ineludiblemente, en mayor o menor intensidad, en cualquier denominación de organización familiar y que son categorías, ya estudiadas con rigor metodológico y están entronizadas en el discurso académico y ciudadano.

Entre los variados hechos que afectan las Estructuras Familiares modernas, sobresalen:

\subsubsection{Modernización del Estado y reformas legislativas.}

La Internacionalización de los Derechos de Infancia y de la Familia, a través de la suscripción de 
tratados, acuerdos y convenciones internacionales, que son firmados y acogidos por la comunidad de Naciones, para garantizar unos mínimos en el respeto Universal de los derechos fundamentales, permite el diseño y la ejecución de leyes y códigos nacionales, para ajustar la complejidad social a la legislación y subsanar parcialmente el desfase entre las normas jurídicas y la realidad.

La Convención Internacional de los Derechos del Niño 1989, es el tratado con mayor cantidad de países firmantes (193), que reúne el mas alto número de Estados partes. Es acogido en Colombia con la Ley 1098 de 2006, Código de Infancia y Adolescencia, que....tiene por objeto establecer normas sustantivas y procesales para la protección integral de los niños, las niñas y los adolescentes, garantizar el ejercicio de sus derechos y libertades consagrados en los instrumentos internacionales de Derechos Humanos, en la Constitución Política y en las leyes, así como su restablecimiento. Dicha garantía y protección será obligación de la familia, la sociedad y el Estado. (Ley 1098 de 2006, Artículo 2²)

Es un asunto vital en la agenda profesional, gubernamental y societal, pues requiere innovaciones trascendentales en la atención y protección que le debe el Estado a la población entre los 0-18 años. Más allá del conocimiento técnico-operativo, exige una mentalidad para trabajar de manera colaborativa entre las áreas del conocimiento y en propiciar el derecho y el deber, de estudiar y comprender los contextos familiares de gran parte de los niños y las niñas y adolescentes, en el sistema judicial: Signados por la exclusión, la pobreza, la deprivación psicoafectiva y una cultura urbana y rural, en tensión permanente entre los distintos actores armados, que se convierten en referentes de este grupo etáreo, en condiciones adversas.

La consideración de que los niños y las niñas y la familia son sujetos prevalentes del Derecho, precisa cambios de cosmovisión y nuevos escenarios en los procedimientos socio-jurídicos, para contribuir a garantizar condiciones de vida dignas a las familias que tienen un miembro menor de edad, comprometido con la infracción de la ley. Acoge esta denominación el imperativo ético de eliminar la violencia contra la niñez, la erradicación del trabajo infantil, la inseguridad alimentaria, la desescolarización y decrecer la morbi-mortalidad en la infancia, en el marco de la protección al planeta tierra.

El Enfoque de derechos en la niñez e infancia, es una premisa universal, que implica políticas públicas y acciones multidisciplinarias, intersectoriales e interinstitucionales, plasmada en los programas que acogen la Primera Infancia, como una construcción conceptual moderna que reconoce la importancia explícita al primer septenio de vida. Las reflexiones en torno a la educación de los niños entre 0 y 6 años se actualizan a la luz del cambio de época, de las concepciones teóricas que sustentan la infancia y de las nuevas necesidades de los niños y las familias.

Prima el derecho a tener una familia, un nombre y un apellido, estudio, vínculo psico-afectivo Es indiscutible e indelegable el derecho a crecer en contextos adecuados, de forma integral, según 
las características del entorno y la obligación -de toda la sociedad- de recibir a las nuevas generaciones de la mejor manera.

La Carta de los Derechos de la Familia, presentada por la Santa Sede a todas las personas, instituciones y autoridades interesadas en la misión de la familia, cristianas o no, en el mundo contemporáneo (1983), con el fin de dar una formulación lo más completa y ordenada posible de los derechos fundamentales inherentes a esta sociedad natural y universal que es la familia, es una ruta en las relaciones civiles, se anticipa en el momento de su formulación y propugna por la igualdad, el respeto a la diversidad, el combate a la pobreza, a la exclusión, al maltrato humano en sus diversas formas.

En el caso colombiano destacan varias de las reformas legales significativas en las dos últimas décadas, para las estructuras familiares: divorcio, compañeros permanentes, violencia intrafamiliar, aborto terapéutico, permiso de paternidad a los hombres, reconocimiento de la seguridad pensional entre compañeros homosexuales -que acrediten convivencia por más de dos años-, custodia compartida, código de infancia y adolescencia, conciliación familiar, entre otros.

El Enfoque de Derechos y el Reconocimiento de la Ciudadanía para la igualdad en la diferencia reconocen los Derechos Civiles y Políticos, los Derechos Económicos Sociales y Culturales y los Derechos al Medio Ambiente y a la Paz. La perspectiva de derechos prioriza los derechos de los excluidos y desposeídos de manera específica a los desposeídos en razón de la discriminación. .... Los enfoques actuales sugieren que la discapacidad tiene unas dimensiones que superan un problema de salud individual $y$, reconoce que se afecta a la persona en relación con su familia, y el contexto político, cultural, social y económico. (Baquero; 2009: www.viva.org.co).

\section{Movilidad Social.}

Expresada en las migraciones de todo tipo, internas (dentro del mismo país), intraurbanos (en una misma ciudad), transnacionales, desplazamiento forzado individual, familiar $y / o$ colectivo.

La migración involucra a muchos miembros de la familia a través de las fronteras nacionales. Incluye a aquellos que partieron, aquellos que se quedaron en sus países, y los que van y viene. Los efectos de la inmigración alcanzan a las generaciones futuras de hijos y nietos de inmigrantes. (Falicov, 2008:26)

El concepto de familia transnacional, sustentado en los procesos migratorios, evidencia nuevas formas de relación y vínculos que se establecen entre los migrantes y sus familias ubicadas en el país de origen. Enfatiza más el componente funcional y emocional, que permite mantener las redes socio-familiares, a través de los límites geográficos y la lejanía física y garantizaría una 
interacción no presencial. Aunque desde la estructura, asuma otras denominaciones la convivencia tanto en el país natal como en el de acogida.

Al igual que en muchos fenómenos recientes, se da la feminización de la migración trasnacional, en tanto la mujer modifica su participación en este proceso y trasciende su papel de acompañante, para desplazarse de manera independiente 0 convertirse en proveedora económica principal, de su familia desde el país donde ha migrado.

Es sabido que procesos masivos de emigración masculina promueven la formación de familias con jefatura femenina y/o masculina, o de hogares extensos; alteran el equilibrio del mercado matrimonial, y hasta pueden modificar la edad del matrimonio (Chant, 1992; Momsen, 1992; Ariza, 2000). (Ariza y de Oliveira; 2004: p 156).

Merece rescatar, los dilemas y vulneración de los derechos fundamentales en el tema de migración ilegal, por sistemas migratorios basados en la xenofobia, la exclusión y el racismo de variado tipo. Además de la crisis financiera de finales del 2008 y lo corrido del 2009, que obstaculiza opciones de integración legal e integral, en los países receptores del éxodo y presenta casos de inequidad e injusticia, como el registrado en junio de 2009:

Claudia Ramírez migrante a Estados Unidos hace 17 años, construyó vínculo familiar, con relación de pareja estable, tres hijos y un negocio de mecánica propio, fue deportada a su natal Manizales y castigada con la prohibición de reingresar, al que fue su país y lo es de sus hijos, que poseen la nacionalidad estadinense. Un sistema familiar sólido, fragmentado por un tecnicismo jurídico, que exige medidas extremas para su reestructuración y somete a la madre/mujer/empresaria, deportada a condiciones de vida injustas y violatorias de su derecho universal de tener y vivir en Familia.

\section{Remesas Familiares}

Derivadas del fenómeno de Movilidad Social, el aporte económico permanente de los migrantes a sus familias, radicada en el país de origen, se ha constituido en un fenómeno monetario de alcance financiero y presupuestal en el Producto Interno Bruto de los países receptores. Destaca en los primeros renglones de Suramérica, el caso de Ecuador y Colombia, que desplazan su población hacia Estados Unidos y España, fundamentalmente.

El término de Remesas Familiares es acuñado a nivel internacional por la ONU, OMI, CEPAL, BID, entre otras y es definido en el Diccionario Especializado en Familia y Género, como un neologismo que transciende la noción económica del fenómeno y requiere procedimientos de atención integral, tanto en el país natal como en los receptores de mano de obra barata.

La acrecentada importancia de los flujos migratorios internacionales en el contexto económico 
reciente, ha convertido a las remesas en una de las principales fuentes de divisas y en un factor equilibrador de los déficits en cuenta corriente, afecta de múltiples maneras la estructura y la dinámica de los hogares, tanto en período de auge como de recesión.

La caída de las remesas -el 7\% en América Latina-, debido en gran parte a secuelas, de la crisis financiera, genera desempleo, caída de ingresos, disminución de flujos migratorios y aumento de deportaciones. Desplome que afectará a cinco millones de familias en la región y determina el retorno voluntarios de cientos de compatriotas al país. (Centro de Estudios de Diálogo Interamericana, 2009).

Todo lo cual incide en la recomposición de las Estructuras Familiares por el cambio en las familias del país de origen, reacomodadas fundamentalmente en tipologías: extensas, ampliadas, familias sin núcleo -gruposconsanguíneos: abuelos/nietos, primos, tíos/sobrinos, hermanos/fraterno- o monoparentales. Lo que da lugar a mudanzas socio-económicas que han impactado localidades regionales y exigen nuevos dispositivos estatales y sociales para comprender e intervenir estas reconfiguraciones y el concepto de Familia transnacional.

A le fecha del presente texto, la estimación del Fondo Multilateral de Inversiones (MIF) del BID, implica un descenso del $11 \%$ de las remesas familiares provenientes de Estados Unidos, para América Latina y el Caribe. Mientras que las de Europa bajarán en un 14\% y de otros países del mundo, en un 4.5\%. (El Colombiano, Agosto 13 de 2009).

Esto exige programas intersectoriales e interinstitucionales que trasciendan la noción económica de la remesa. Para la ilustración:

2 Modelo de retorno voluntario con base en desarrollo empresarial operado por la Universidad Sergio Arboleda de Bogotá, que con cooperación internacional, financia proyectos productivos para garantizar los ingresos fijos al regreso a Colombia, y la recomposición de las estructuras familiares.

Mi casa con Remesas, proyecto en convenio con la Cancillería de la República, seis Cajas de Compensación, el Banco Interamericano de Desarrollo y Asocajas, para garantizar la adquisición de vivienda familiar.

Fomento financiero y educativo de la capacidad de ahorro, de las familias receptoras de las remesas, que garanticen rentabilidad y sostenibilidad a futuro.

\section{Desplazamiento forzado.}

Si mediar más análisis de un fenómeno ya sobre diagnosticado, se presenta el informe mas reciente al respecto: 
“..en efecto, el $55,5 \%$ de los grupos familiares tenía tierra, de los cuales a un $94 \%$ se les despojó o tuvieron que abandonar la propiedad, y el $78,9 \%$ animales, con el agravante de que un $92,4 \%$ los perdió -ya sea que se concibieran como activos o como capital de trabajo...Como consecuencia de lo anterior, en primer lugar se ha producido un grave empobrecimiento de los grupos familiares víctimas del desplazamiento forzado, lo que ha afectado claramente sus posibilidades de consumo y de ahorro. Los ingresos que se han dejado de percibir en estos 11 años por los grupos familiares que abandonaron tierras, animales 0 viviendas no rurales ascendieron a la suma de 49,7 billones de pesos (a precios de 2008). Esta cifra representa el $11,6 \%$ del PIB a precios corrientes de 2007. Las menores posibilidades de consumo y ahorro de la población desplazada puede observarse al analizar las variaciones ocurridas en sus índices de pobreza e indigencia. Antes del desplazamiento cerca del $49 \%$ de los grupos familiares generaban ingresos mensuales superiores a la línea de pobreza y el $68,5 \%$ por encima de la línea de indigencia. Después del desplazamiento tales índices caen dramáticamente, ya que sólo el 3,4\% y el $19,3 \%$ generan ingresos familiares mensuales superiores a las líneas de pobreza e indigencia, respectivamente. En segundo lugar, tras el desplazamiento de millones de colombianos, importantes extensiones de tierra de calidades productivas nada despreciables no están siendo aprovechadas eficientemente o se han destinado a ganadería extensiva, lo cual genera una disminución de la producción agrícola del país. Esto podría constituir una de las causas del menor dinamismo del PIB del sector en los últimos años. (Garay: 2009).

En el orden del desplazamiento intracitadino, en el contexto local de Medellín, en el año en curso, ha aumentado significativamente el desplazamiento forzado intraurbano, como un mecanismo de protección de las familias hacia los niños, las niñas y los adolescentes que son reclutados de manera involuntaria por los actores armados o están en riesgo de morir. En el semestre enero-julio 2009, las cifras superan las denuncias recibidas desde el 2004 y empíricamente se establecen variaciones en dichas estructuras familiares.

\section{Desigualdad en el Capital Humano.}

Esto se evidencia en la vinculación laboral de las mujeres y la constante recarga doméstica en ellas. Actualmente hay 100 millones de mujeres lati noamericanas, el 53\% de la población activa femenina trabaja de forma remunerada, pero el $54 \%$ carecen de contrato y el sueldo que reciben es el $70 \%$ del que obtienen los hombres. En el rango de 20 y 40 años, este porcentaje asciende hasta el $70 \%$. Aunque ha aumentado la participación laboral femenina de $37,9 \%$ en 1990, al 70\% en el 2009, la tasa de participación femenina es aún inferior a la masculina y disminuye cuando se trata de mujeres casadas. "Hoy las mujeres comparten con los hombres el tiempo de trabajo remunerado, pero no se ha generado un proceso de cambio similar en la redistribución de las carga de las tareas domésticas. (OIT y PNUD; 2009: http://www.undp.org/)

Otro elemento significativo de la desigualdad, se explica en términos de la pobreza extrema o indigencia, donde los registros estadísticos siguen reportando la mayor causa de ella, ya que los 
estratos altos tienen acceso a capital humano, educación de calidad y los estratos bajos no. Ello genera desigualdad laboral e imposibilidad de acceder a empleos cualificados, además de que en momentos de dificultad económica las mujeres trabajadoras son las más vulnerables y aplica la reproducción determinista de familias con bajos o nulos ingresos y deteriorada calidad de vida, expresada en el alto porcentaje de familias monoparentales con jefatura femenina.

La pobreza dura e indigencia alteran el funcionamiento de las familias de este rango, en tanto los hijos y las hijas mayores, tienen que asumir papeles "parentificados", en calidad de proveedores o coprovidentes económicos y en gran parte, figuras de protección psico-afectiva y autoridad con los hermanos menores u otros miembros de la familia en situación de discapacidad -mental, cognitiva o física- o dependencia.

\section{Desarrollo Sustentable.}

Destaca el carácter de la familia como actor y movimiento social, con protagonismo en la esfera pública. Los conceptos de inclusión, equidad, justicia social, perspectiva de género, multiculturalidad, enfoque de Derechos, sustentan este nuevo encargo, bajo el precepto de garantizar la utilización eficiente de los recursos internos y externos, incrementar y diversificar la generación de ingresos según el entorno y permitir la libertad de expresiones culturales, lúdicas y políticas que procuren el cambio social en escenarios de decisión y concertación del desarrollo local. Ello permitiría mutar los modelos de exclusión, hacia la inclusión, acordes al contexto social y político que atraviesan las nuevas configuraciones ciudadanas y familiares.

Más allá de sus implicaciones sociales y económicas, se propone otro énfasis para asumir los preceptos de la sostenibilidad, en eventos destacados, que afectarían las estructuras familiares modernas:

6.1. Viviendas de Interés Social, política pública del gobierno, que subsidia a los estratos 1 y 2 y a las familias en situación de desplazamiento o de reinserción, pero que en gran parte no garantizan la seguridad arquitectónica. Debe impulsar criterios básicos de saneamiento básico, atención sobre sismo-resistencia, manejos de aguas, rutas de evacuación y formas amables con el medio ambiente. Espacios que faciliten la convivencia, la formación, la comunicación y la vida sana, según los recursos y el contexto socio-económico.

6.2. Diseños arquitectónicos de vanguardia, de tipo ecológico, para garantizar materiales ecológicos, formas de máxima utilización de la luz, el aire, las propiedades naturales de los elementos, la preservación de los recursos no renovables, la armonía con el entorno, y las prácticas.

6.3. Edificios sostenibles: crear una cultura ecológica en empresas y viviendas. Las 
construcciones ambientales, integran el principio de la comodidad en el trabajo, el hogar y los sitios recreativos, con el cuidado del medio, considerando el reciclaje y reutilización de materiales, ahorro de agua y energía, espacios amigables para respirar (no fumadores, evitar agentes contaminantes). Colombia creo el Consejo Colombiano de Construcciones sostenibles en 2008, que contribuye a la tendencia de una arquitectura urbana, acorde con el desarrollo sostenible y objetivos de mejorar la calidad de vida de las familias, las corporaciones y las comunidades.

\section{Empresas Familiarmente Responsables.}

En correspondencia con el concepto moderno de la Responsabilidad Social Empresarial (RSE), emerge la denominación de Responsabilidad Familiar de las Empresas, como una faceta significativa en la línea de la Conciliación entre el mundo del trabajo y la familia. Habida cuenta de que los programas que acogen esto también pretenden optimizar el rendimiento laboral y asegurar las ganancias de la entidad.

... la familia, célula básica de nuestra sociedad queramos o no queramos, se ha visto obligada, ...a adaptarse a una época de grandes contrastes, grandes cambios. Así, por ejemplo, se ha pasado de un modelo familiar y laboral en el que la división de roles de género era dominante a un nuevo modelo en que tanto mujeres como hombres participan directamente en el mundo del trabajo remunerado, y de ahí el establecimiento de leyes como la española, la Ley 39/1999 para la conciliación de la vida familiar y laboral -y dígase de paso con el lapsus de no incluir la "vida personal"-, que consiste fundamentalmente en la procuración de una efectiva equidad en la distribución de las responsabilidades familiares y laborales como elemento imprescindible (pero o el único) para la efectiva igualdad de oportunidades entre hombres y mujeres (González; 2008:2).

Una empresa es familiarmente responsable cuando promueve y permite que sus trabajadores puedan conciliar de manera satisfactoria y equilibrada la relación entre su trabajo y su familia. Lo cual incluye programas de salud emocional, flexibilidad en los horarios de trabajo, criterios de equidad de género y eliminación de la violencia y el hostigamiento laboral y el acoso sexual.

Asimismo de apoyo en igualdad de oportunidades, inclusión etárea, étnica, religiosa, sexual, cultural, política, sistema de ética laboral y respeto a la familia en cualquiera de las modalidades, como un valor corporativo. Esta cultura, además de cumplir orientaciones internacionales, garantizaría un mínimo de igualdad y equidad, en el cumplimiento de las funciones básicas de la familia y en el desarrollo integral de sus miembros.

\section{Relación familia escuela}

Entendida esta relación dialéctica en la fusión de los procesos de socialización primaria y 
secundaria, son destacados algunos puntos generales para integrar los dos sistemas más importantes en las primeras etapas vitales: familia y escuela. Ratificando el principio que rige la psicología evolutiva y los programas que en la actualidad se nombran de la Primera infancia: la importancia del primer septenio de vida, el más fundamental.

Las mudanzas familiares evidentes, generan nuevos sujetos que ingresan al período lectivo y exige novedosos dispositivos pedagógicos, didácticos y de atención integral. Acorde con los preceptos de la Carta Magna y de la participación ciudadana, es imperativo construir una cultura de participación, del disenso, de la convivencia en la diversidad, disciplina, de las relaciones democráticas, la responsabilidad civil de los padres o figuras parentales por las acciones de los hijos en el ámbito escolar.

Bajo la Corresponsabilidad, establecer los compromisos de los equipos directivos y de los establecimientos educativos. Garantizar la admisión y permanencia en la escuela como un derecho fundamental. Renovar el sentido de educar, fortaleciendo asuntos básicos como identidad, diferencia y diversidad. Reconocer los nuevos contextos urbanos hostilizantes -donde el mundo es una amenaza para el dicente-, generadores de violencia y hostigamiento escolar, y las conductas temerarias: tales como deportes radicales, tribus y exploradores urbanos.

Contrastando la internacionalización de los niños y las niñas considerados como sujetos prevalentes de derecho, se consolida la Patologización de la infancia, en el sistema educativo, las instituciones y profesionales de la salud y las familias o los cuidadores primarios, con la identificación colectiva de los niños bajo el rótulo de hiperactivos y el suministro del metilfenidato o ritalina, como solución a los conflictos de una infancia inquieta, curiosa que demanda atención psico-afectiva. La estigmatización de por vida, acarrea conductas vitales que caracterizan a una parte significativa, de la última generación, pero aún no se estudian los efectos en sus vínculos eróticos -afectivos.

\section{Homoparentalidad.}

La tendencia a defender nuevas formas de familia, como la que se originaría de uniones entre homosexuales (dos personas del mismo sexo), evidencia un cambio de mentalidad en la noción tradicional de familia. Ello implica asumir nuevos principios reguladores para la vida social, especialmente en referido a la relación entre adultos y niños. La legalización de matrimonios entre personas del mismo sexo modifica el precepto básico del matrimonio, la priva de su significado originario y de su tradicional valor social.

Bajo la denominación de familias homoparentales, se acogen las nuevas tendencias jurídicas de reconocer las uniones homosexuales, en el contexto civil y patrimonial. Esta opción protegería también la posibilidad de la procreación asistida y el derecho de los niños a la filiación y a 
sostener un vínculo parento-filial, independiente de la opción de género de sus progenitores, Pero todavía no se homologan estas uniones, al matrimonio heterosexual establecido por la legislación. De lo que se deriva que es un concepto con función social, pero como tal no aplica o es vinculante para el Derecho.

En Colombia, recientemente la Corte Constitucional, aprobó varias disposiciones a favor de las parejas del mismo sexo, en una afirmación a la diversidad sexual y a una tendencia planetaria. Reconoce derechos de herencia, beneficios en pensiones y salud, permite que los transexuales cambien el nombre en varias ocasiones y proclama el respeto y la igualdad que merecen las personas y parejas homosexuales, en los ámbitos laborales, educativos y sociales.

\section{TICs-Tecnologías de la información.}

Más allá de la evidente y sobrediagnosticada realidad e impacto de las TICs en la sociedad moderna y en el ámbito familiar, resalta el requerimiento de la Inclusión social y cultural y su uso en la escuela, como forma de facilitar el aprendizaje, capacitar e instruir a los sectores excluidos y vulnerables y disminuir la enorme brecha educativa entre los estratos económicos y la ciudad y el campo. Con el reconocimiento de su influencia en el proceso de socialización primaria y secundaria, se requiere diferenciarlos de la comunicación y analizar los usos y abusos en el contexto escolar y familiar.

Las TICs enfrentan una paradoja propia del milenio: las bondades del avance tecnológico y la modificación sustancial de los conceptos de intimidad, privacidad, autonomía personal y voluntaria de con quién, cómo y cuándo se interacciona: éste es el derecho a usar el ciberespacio según los límites innatos a la convivencia familiar y ciudadana, para no invadir espacios propios de cada sujeto y además, exponerlos en público con el agravio que genera la perversión informática, la invasión de las redes (Facebook, twiter) y la morbosidad propia de los "realitis" tan en boga, de ser espectadores de la vida privada del otro.

Es preciso reflexionar acerca de cómo se afecta lo íntimo, lo privado, con el fenómeno contemporáneo de la revolución informática, la manera como ésta promueve nuevas formas de ser, cómo exhibe otras subjetividades. En el entorno familiar es innegable el papel mediático y socializador secundario que cumplen las TICs y con ello influyen sustancialmente en la estructura y el funcionamiento familiar, generando ventajas en el cuidado parental, las tareas domésticas, las conexiones globales, pero al mismo tiempo crea referentes emocionales y afectivos, que distorsionan el vínculo primigenio y prioriza las relaciones con las webredes, el sexo y la pornografía virtual, el acoso electrónico, entre otros.

Nuevas rutas genera esta tendencia, en tanto en los procesos de atención socio-familiar a nivel gubernamental y privado, ya incursiona en la virtualidad (tipo Chat, redes, video-conferencias, circuito cerrado de televisión), para realizar entrevistas con familias en sesiones múltiples. 
Cumpliendo también un papel significativo en la permanencia de los vínculos afectivos en las familias transnacionales.

\subsection{A modo de conclusión.}

Los actuales modelos y tendencias de la familia pueden resumirse en tres palabras, complejidad, contingencia y contradicción. Complejidad en el sentido de la coexistencia y entrelazamiento de las formas familiares; contingencia de relaciones, por las opciones y accidentes que siguen al debilitamiento de la regulación institucional; y contradicción entre preferencias, entre situaciones y recursos. (Therbon Goran; 2004: 40).

Las investigaciones recientes, (gran parte de ellas realizadas en las universidades, tanto en pre como posgrado), desvirtúan la idea popular de que la familia se esté acabando o que tienda a desaparecer. Evidencian que han surgido nuevas formas que, como la simultánea, se crean como respuesta de hombres y mujeres de establecer una segunda relación y por los cambios en los patrones culturales y legales.

Existen otras denominaciones, sobre el concepto de Familia, pero que no referencian tanto su estructura o tipología, sino características particulares, que recogen cambios en la modernidad: Familias: Cuidadora, transnacionales (migración), numerosas (para recibir subsidios parentales), de acogida, transculturales. Estas particularidades aplican a cualquier estructura familiar, y no asignan una denominación o término particular sobre su tipología.

En este entramado actual emergen términos de reciente acuña, que permean las Estructuras Familiares, y exigen niveles de comprensión innovadores y acordes con el correr de los tiempos. No son fenómenos recientes, sino que irrumpen con todo su impacto integral y en las agendas legislativas, en tanto afectan sustancialmente la calidad de vida, e incluso la morbi-mortalidad.

Algunos de los nuevos vocablos en los escenarios familiares, de orden psiquiátrico y psicológico, son: Violencia y hostigamiento en las escuela, Bullying, síndromes del Bournet, de alienación parental, mobing: estrés laboral. Adicción al trabajo: trabaja-adicto. Adicción y sexo virtual. Otros neologismos son: Procreación asistida, empresas familiarmente responsables, coparentalidad, custodia compartida, Interculturalidad, resiliencia familiar, familias: transnacionales, transculturales, homoparentales.

La Familia como el más significativo sistema relacional, requiere nuevas estrategias y paradigmas para su estudio, comprensión e intervención, que abarcan todos los estamentos de la sociedad.

En esa línea, el Estado Colombiano debe generar programas que garanticen atención integral a las familias pobres. Según datos recientes de la Misión de la Pobreza, (Dane: 2009), pese al 
crecimiento económico hay condiciones sociales, económicas y políticas que les impiden a 22 millones de colombianos que están en la línea de pobreza, mejorar sus condiciones de vida. Puesto que la pobreza afecta de manera específica a las mujeres, a los pueblos indígenas y a los afrodescendientes, es esencial que las políticas de contracción de la pobreza y de la desigualdad contemplen el fortalecimiento de dichos grupos.

Ante la extrema pobreza y la inequidad, las familias en esta categoría, cumplen un círculo vicioso, o determinista: tienen menos acceso a la educación y así las posibilidades de empleo son menores, viven en casas con deficientes materiales, o en tugurios, en zonas de alto riesgo, las niñas/adolescentes procrean hijos y suspenden la escuela, por lo tanto, contribuyen a sostener la línea de la pobreza.

Estas circunstancias endémicas de desigualdad, exclusión y deprivación de las necesidades básicas, influyen en las estructuras familiares actuales. Para la ilustración, el aumento de familias monoparentales, en cabeza de niños/niñas y adolescentes y las familias sin núcleo por las migraciones transnacionales.

Redimensionar las Políticas Públicas de la Familia, implica superar la subsidiaridad o énfasis en el subsidio económico, para paliar necesidades básicas, coyunturas y emergencias, y brindar atención integral en condiciones adecuadas en las interacciones ecosistémicas.

Todo lo susodicho, bajo la égida de la corresponsabilidad, Estado-Sociedad Civil-Familia, que articula integra acciones preventivas, promocionales, educativas y de protección integral, considerando los Movimientos sociales, la Ética civil, la Ciudadanía y la Participación comunitaria y política.

\section{Referencias Biobliográficas}

Adell, M (2002). Estrategias para mejorar el Rendimiento Académico de los Adolescentes. Ediciones Pirámide. 19-40.

Andrade, M., Miranda, C. \& Freixas, I., Rendimiento Académico y variables modificables en alumnos de 2do Medio de Liceos Municipales de la Comuna de Santiago. Extraído el 18 de noviembre de 2005 desde: http://www.unesco.cl/medios/biblioteca/documentos/eaprendizajes_rendimiento_a cademico_2_medio_santiago.pdf?menu=/esp/atematica/evalcontexinterc/docdig.

Ariza Marina y de OLIVEIRA Orlandina. (2004). Familias, pobreza y necesidades políticas en México y Centroamérica. En: Cambios de las familias en el marco de las transformaciones globales: necesidad de políticas públicas eficaces. Santiago de Chile: CEPAL. Comisión Económica para América Latina y el Caribe. Naciones Unidas. 
Arriagada Irma (2009). Globalización y transformaciones familiares en América Latina. En: Revista de Trabajo Social No 7/8. Medellín: Departamento de Trabajo Social, Universidad de Antioquia. Vieco Ltda.

Baquero Torres, María Inés (2009). El enfoque diferencial en discapacidad: un imperativo ético en la revisión del Plan de Ordenamiento Territorial de Bogotá D.C. En: Corporación Viva la Ciudadanía, semanariovirtual@viva.org.co www.conciudadania.org

Baumrind, D. (1968), Authoritarian v. Authoritative parental control. Adolescence, 3, 255-272. Bronfenbrenner, U., (1987), La Ecología del Desarrollo Humano, Barcelona: Paidos.

Caja de Compensación Familiar- Comfenalco Antioquia. Red de Programas Universitarios en Familia, (Nodo Antioquia). (2009). Seminario Nacional sobre Familia: Familias Contemporáneas: Transformaciones y Políticas Públicas de la Familia.). Medellín.

Casanova, P., García, C., De la torre, M., De la Villa, M., (2005), Influence of Family and SocioDemographic Variables on Students with Low Academia Achievement. Educational Psychology, 25(4), 423-435.

Centro de Estudios de Diálogo Interamericana. (2009). Informe Migración y Remesas en Tiempos de Recesión. Medellín: El Colombiano, julio 2009.

Clemente, R., Hernández, C. Contextos de Desarrollo Psicológico y Educación. (151-169), Aliibe.

Coll, C., Miras, M., Ornibia, J. \& Solé, I. (1998). Psicología de la Educación. Barcelona: Edhasa.

Covadonga, R.M., (2001), Factores Vinculados al Bajo Rendimiento Académico. Revista Complutense de Educación, 12(1), 81-113.

Espinoza, E., (2006), Impacto del Maltrato en el Rendimiento Académico. Revista Electrónica de Investigación Psicoeducativa, 4(9), 221-238.

Falicov, Celia J. (2008). El trabajo con inmigrantes transnacionales: expandiendo los significados de Familia, Comunidad y Cultura. En: Redes No 20. Barcelona: Paidós.

Fuentes, M., Motrico, E., y Bersabé, R. (2001). Análisis Psicométrico de dos Escalas para Evaluar Estilos Parentales. Revista Psicothema, 13(4), 678-684.

Garay Salamanca Jorge Luis, BARBERI GÓMEZ Fernando, y CELEIDE 
Prada Gladys (2009). Impactos económicos del desplazamiento forzado. Proceso Nacional de Verificación de la Comisión de Seguimiento a las Políticas Públicas sobre el Desplazamiento Forzado. En: Hechos del Callejón. No 47. Bogotá: Área de Desarrollo, Paz y Reconciliación del PNUD. http://indh.pnud.org.co/

Garay, Jorge Luis. (2002). Repensar a Colombia. Hacia un nuevo contrato social. Bogotá: Tercer mundo editores.

González Martín, Nuria (2008). El derecho de familia en un mundo globalizado: la adopción internacional. En: IV Congreso Internacional Derecho de Familia, Universidad d e Antioquia. Medellín: Facultad de Derecho y Ciencias Políticas. (CD).

Gracia, E., (2002), El maltrato infantil en el contexto de la conducta parental: Percepciones de padres e hijos. Psicothema, 14(2), 274-279.

Gracia, Lila, Musitu, (2005), Rechazo Parental y Ajuste Psicológico y Social de los Hijos. Salud Mental, 28(2), 73-81.

Hernández Córdoba, Ángela. (1997). Familia, Ciclo vital y Psicoterapia sistémica breve. Santa fe de Bogotá: El Búho.

Hernández, C., (1996), Bronfenbrenner y los Modelos Ecológicos. En R. Clemente, C. Hernández, Contextos de Desarrollo Psicológico y Educación; (91-1 10). Aljibe.

Hernández, G. E. (1998). Una aproximación al análisis cualitativo de los datos. En: Enseñanza e investigación en psicología.

México: Nueva Época. CNEIP.

Herrera, P. (1997) La Familia Funcional y Disfuncional, un indicador de salud. Rev. Cubana Med gen Integr; 13(6): 591-5. Extraído el 20 de Enero de 2007 desde:http://www.bvs.sld.cu/revistas/ped/vol71 199/ped06199.html.

Lamborn, S.D., Mounts N.S., Steinberg, L. \& Dornbush, S.M. (1991), Patterns of competence and adjustment among adolescents from authoritative, authoritarian, indulgent and neglectful families. Child development, 62, 5, 1049-1065.

Londoño, V. (2005), Relación entre el estilo de autoridad ejercido por los padres de familia y el Rendimiento Académico de los niños y niñas entre los 8 y 11 años de edad escolarizados en los niveles 2 a 5 de básica primaria del municipio de ltaguí.

Memoria para optar al título de psicóloga, Facultad de Psicología, Universidad de San Buenaventura, Medellín. 
Lozano, A., (2003) Factores Personales, Familiares y Académicos que Afectan al Fracaso Escolar en la Educación Secundaria. Revista Electrónica de Investigación Psicoeducativa y Psicopedagógica, 1(1), 43-66.

Martínez, V. (1996). Factores determinantes del Rendimiento Académico en la enseñanza media. Psicología Educativa, Vol. II, 79,90.

Moreno, M.C., Cubero, R., (1990) Relaciones Sociales: Familia, Escuela, Compañeros, Años preescolares. En Marchesi, A., Coll, C., Palacios, J. (Eds). Desarrollo Psicológico y Educación. Madrid: Alianza.

Musito, G., Román, J., Gracia, E., (1988), Familia y educación: Prácticas educativas de los padres y socialización de los hijos. Barcelona: Labor.

OIT-Organización Internacional del Trabajo y PNUD-Programa de Naciones Unidas para el Desarrollo. (2009). Trabajo y Familia: hacia nuevas formas de conciliación con corresponsabilidad social. En: 98 Conferencia Internacional del Trabajo. Ginebra.

Pérez, F., Fuster, E. \& Musitu O., (1988) Diferencias en los Tópicos de Comunicación entre Padres e Hijos según la Dirección de la Comunicación y las Variables Sexo, Edad y Status. Cuadernos de Consulta Psicológica, 4, 31-41.

Pontificio consejo para la familia. (1983). Carta de los derechos de la familia. $\quad R$ o m a : Santa Sede (versión electrónica).

Quintana, J. (1993). Pedagogía Familiar. Madrid: Narcea.

Quintero Velasquez, Ángela María (2007). Diccionario Especializado en Familia y Género. Buenos: Aries: Lumen/Hvmanitas.

Seguel, A., Holmes, Z., Venegas, K., Alcérreca, F., y Salamanca, R.(2000) Factores Socio Emocional Afectivos Y Separación De Los Padres En Niños De Tres A Cuatro Años. Extraído el 15 de noviembre de 2005 desde: http://www.geocities.com/Heartland/Farm/8810/investig/separacl.html.

Sorribes, M., García, F., (1996), Los Estilos Disciplinarios Paternos. EnSteinberg, Dornbusch \& Brown, (1992), Ethnic Differences in Adolescent Achievement: An Ecological Perspective. American Psychologist, 47(6), 723-729.

Therbon Goran. (2004). Familias en el mundo. Historia y futuro en el umbral del siglo XXI En: 
CEPAL. Comisión Económica para América Latina y el Caribe. Cambios de las familias en el marco de las transformaciones globales: necesidad de políticas públicas eficaces. Santiago de Chile: Naciones Unidas.

www.multiversidadreal.org/concepto2.asp? mnu=2

www.undp.org/spanish/publications/pdf/undp_ilo.pdf

Xinyin Chen (1997). Authoritative and Authoritarian Parenting Practices and Social and School Performance in Chinese Children. International Journal of Behavioral Development, $21(4), 855-873$.

'Ver: Morín: www.multiworld.org

${ }^{2}$ Tal como está consignado en la investigación documental Diccionario especializado en Familia y Género, Lumen/Hvmanitas, 2007.

${ }^{3}$ Familias tradicionales: Nuclear, extensa, ampliada, familias sin núcleo-grupos consanguíneos. Nuevas organizaciones: simultáneas, monoparentales, homoparentales.

Hogares no familiares: hogar, hogar unipersonal, pareja/díada conyugal.

${ }^{4} \mathrm{Ha}$ sido ratificada por todos los Estados del mundo, con excepción de Somalia y Estados Unidos.

${ }^{5}$ González Martín, Nuria, "Acciones positivas: orígenes, conceptualización y perspectivas", Torre Martínez, Carlos, de la (Coord.), El derecho a la no discriminación, México, CDHDFCONAPRED-UNAM, 2006, pp. 307 y ss; así como González Martín, Nuria et Chávez Sánchez, Odalinda, Dos temas torales para los derechos humanos: acciones positivas y justiciabilidad de los derechos sociales, México, Comisión Nacional de los Derechos Humanos, 2008, pp. 1-113.

${ }^{6}$ Movimiento más difundido en Argentina. Propone reflexión e iniciativas integrales y preventivas. 